\title{
INTERACTIVE MOTION PLATFORMS AND VIRTUAL REALITY FOR VEHICLE SIMULATORS
}

\author{
EVŽEN THÖNDEL
}

\author{
Pragolet, s.r.o., Director and Czech Technical University in Prague, assistant professor at the Department of \\ Electric Drives and Traction \\ correspondence: thoendel.jr@pragolet.cz
}

\begin{abstract}
Interactive motion platforms are intended for vehicle simulators, where the direct interaction of the human body is used for controlling the simulated vehicle (e.g. bicycle, motorbike or other sports vehicles). The second use of interactive motion platforms is for entertainment purposes or fitness. The development of interactive motion platforms reacts to recent calls in the simulation industry to provide a device, which further enhances the virtual reality experience, especially with connection to the new and very fast growing business in virtual reality glasses. The paper looks at the design and control of an interactive motion platform with two degrees of freedom to be used in virtual reality applications. The paper provides the description of the control methods and new problems related to the virtual reality sickness are discussed here.
\end{abstract}

KEYWORDS: Motion platform, motion cueing, simulator, simulation, virtual reality, VR sickness.

\section{INTRODUCTION}

Interactive motion platforms are intended for a simulation where direct interaction with a human body is required. This type of simulators is e.g. a motorbike or bicycle simulator or other types of vehicles where direct interaction with the human body is used for controlling the vehicle.

A simulator with an interactive motion platform is a closed loop system, where a human being is a part of the system. In contrast to standard humanin-the-loop systems [1], the human does not interact with the system through control elements (such as a steering wheel or pedals) but creates forces and torques which are directly measured and used as input to a mathematical model.

The structure of the closed loop system is shown in the next picture. The structure and principle of individual blocks are further discussed.

\section{Motion Platform}

The purpose of a motion platform in simulators is to reproduce motion effects, such as acceleration, and position towards gravity. Different types and principles are discussed in the literature [2]. The important parameter of each motion platform is the number of degrees of freedom (DoF) and the range of motion in all directions. The most widely used motion platforms today have 2, 3 or 6 DoF.

In the case of simulators of land vehicles, the dominant motion is rotation around the horizontal axis. This motion can also be used for reproducing linear accelerations (by using a motion cueing algorithm[3]). The second aspect which must be considered, when designing a new motion platform, is the final price which significantly grows with the number of degrees of freedom.

A motion platform with two degrees of freedom is the first design and implementation of an interactive motion platform. An extension with a horizontal rotation of 360 degrees is considered in the future, to avoid or to solve a problem connected with virtual reality sickness.

The design of the $2 \mathrm{DoF}$ interactive motion platform is shown in the picture below.

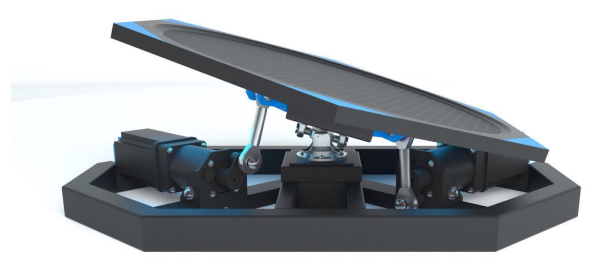

Figure 1. Design of the motion platform.

All kinematic and dynamic parameters are summarized in the following table:

\begin{tabular}{|c|c|}
\hline Maximum payload & $150 \mathrm{~kg}$ \\
\hline Tilt angle & 16 degrees \\
\hline Degrees of freedom & $2($ Pitch and Roll) \\
\hline Maximum tilt rate & 100 degrees $/ \mathrm{s}$ \\
\hline Maximum tilt acceleration & 500 degrees $/ \mathrm{s}^{2}$ \\
\hline Power supply requirements & $230 \mathrm{~V} / 50 \mathrm{~Hz}, 16 \mathrm{~A}$ \\
\hline Weight & $80 \mathrm{~kg}$ \\
\hline
\end{tabular}

TABLE 1. Kinematic and dynamic properties. 


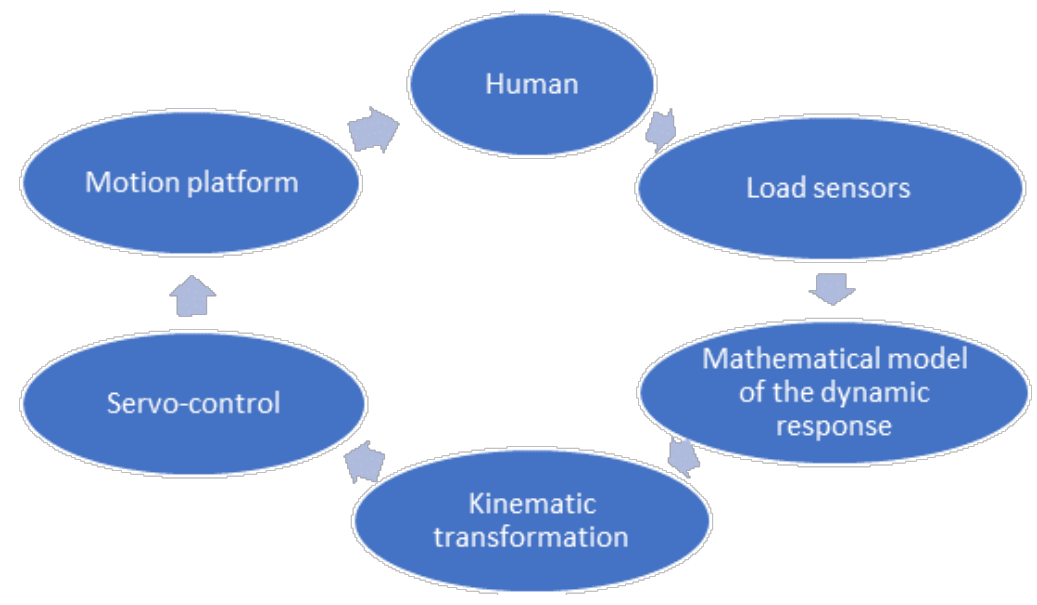

FiguRE 2. Structure of the system with an interactive motion platform.

\section{Mathematical Model of the DYNAMIC RESPONSE}

A mathematical model of the dynamic response reads information about the acting forces and torques and calculates the response of the motion platform. Besides the input from the human, the mathematical model of the dynamic response can also read signals from a superior mathematical model where the dynamic response of the simulated vehicle is implemented.

An implementation of the mathematical model of the dynamic response is shown in the next picture. This structure applies a motion cueing algorithm as well as a model of direct dynamic response (called stiffness in the following structure). The principle of a motion cueing algorithm is described in detail in the previous author's publications 4, and will not be discussed here.

A model of the direct dynamic response can be any dynamic system which reacts directly to forces measured on the motion platform. One possible use of the interactive motion platform is rehabilitation or fitness where the model can implement a system of the load. One example is presented in the next picture where a simple model of a rubber ball is shown.

All mathematical models have been implemented in MATLAB/Simulink and directly compiled to the control hardware. This method of programming is very effective, and it allows the motion platform to also be used in research projects $[\underline{5}$.

\section{LoAd SEnsors}

As discussed above, the main innovation of the new motion platform is the possibility to measure forces and torques which are created by a person standing or sitting on the motion platform. Four load cells, weighing $100 \mathrm{~kg}$ each, are used to measure and further calculate the position (center of gravity) and the intensity of the loading force.

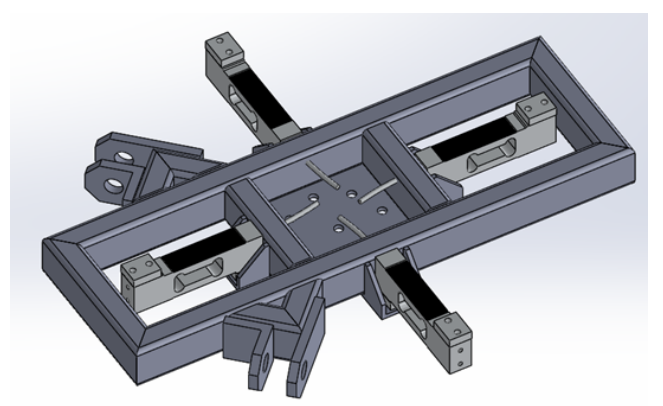

FiguRE 3. Load sensors attachment.

\section{The Use in Virtual Reality}

There has been fast growth in virtual reality over the last two years, especially connected to the use of virtual glasses. New applications and technologies are continuously being researched.

The presented motion platform is ideally suited for vehicle simulators where virtual glasses are used to generate visual perception.

Several designs of applications have been created, and the first real application of a kayak simulator has been finished in 2016 6. The first test and the response from many users show a promising potential for business success and further technological enhancement of the use of VR glasses because it significantly reduces the occurrence of virtual reality sickness.

\section{Virtual Reality Sickness}

Virtual reality sickness is a common problem which is often discussed. Any mismatch between what is seen and what is felt can lead to virtual reality sickness. The motion platform can reproduce a wide range of motion effects, and therefore it contributes to the reduction of the probability of occurrence of virtual reality sickness. However, two degrees of freedom do not cover all motion directions. The horizontal rotation especially is often mentioned in relation to this phenomenon, and it is recommended not to rotate the camera in the VR world at all[7] or to use a 


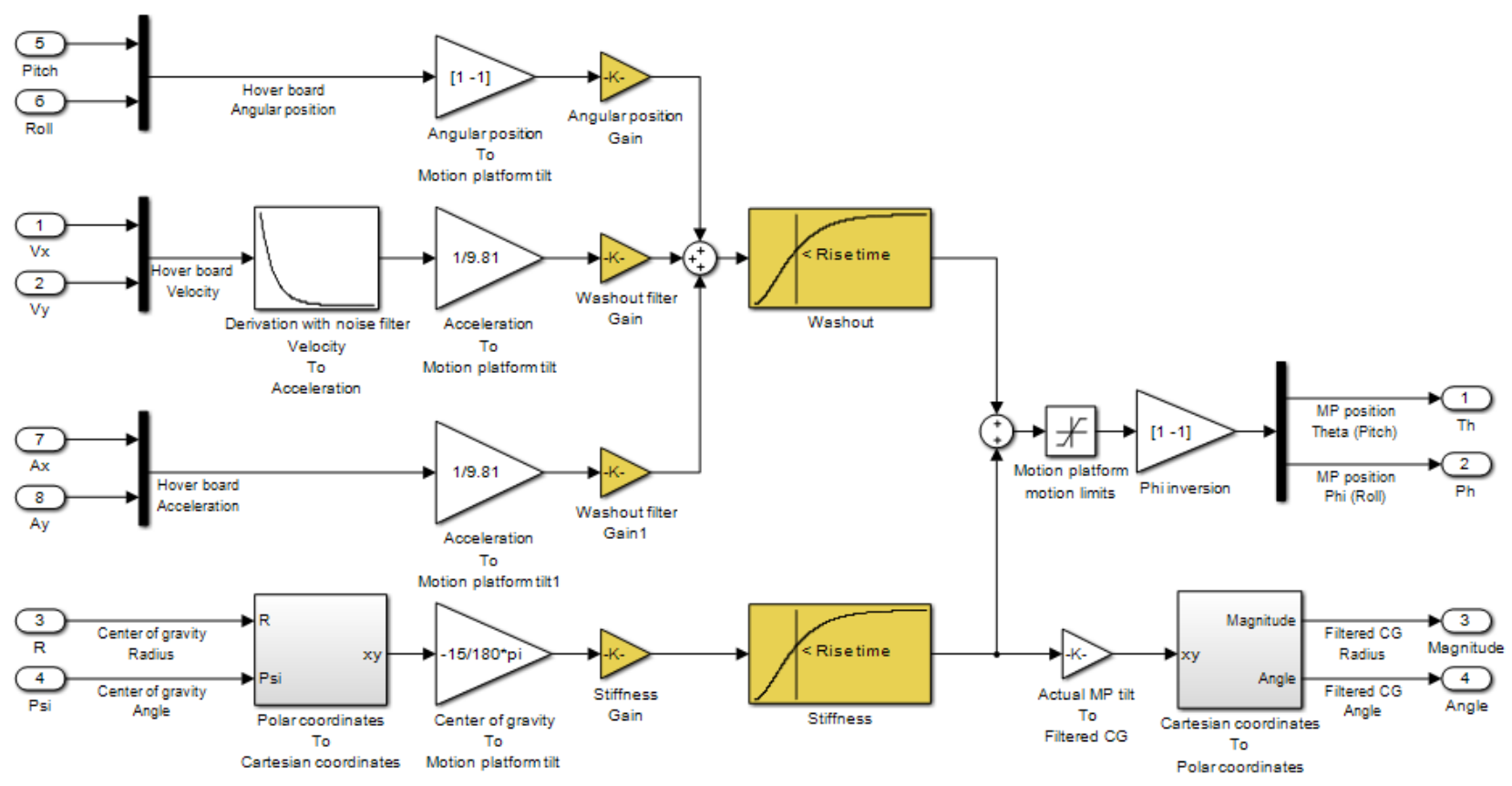

FiguRE 4. Mathematical model of the dynamic response.

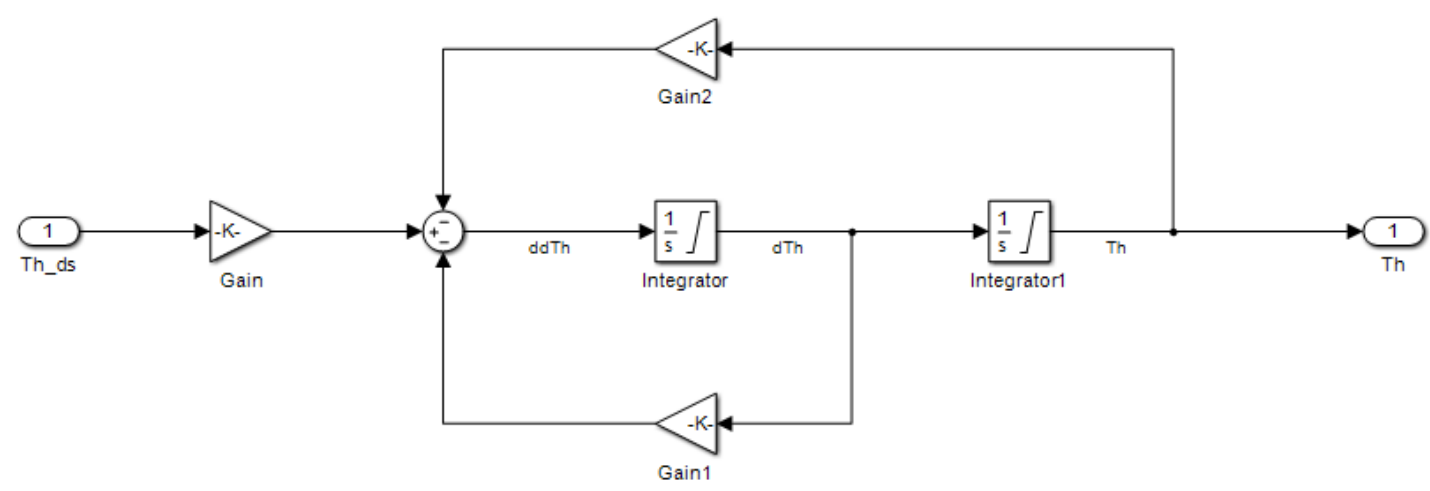

FiguRE 5. Mathematical model of the direct dynamic response - rubber ball.
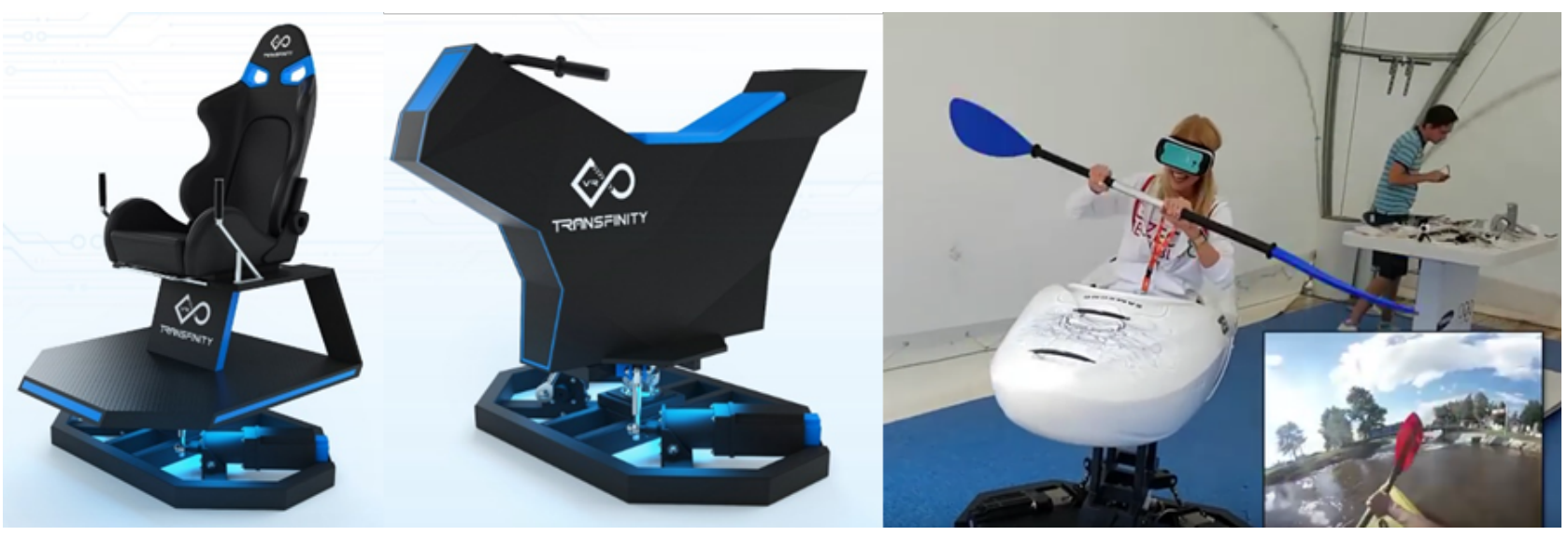

Figure 6. Application of the motion platform. 
motion platform with a rotary axis 8 . The vertical linear acceleration can partially be compensated for by rotating the motion platform.

Therefore, it is planned to extend the construction with a rotation of 360 degrees. This new design will be an optimal construction for simulators using VR headsets with respect to the range of reproduction of motion effects and the financial costs.

\section{Conclusion}

A new interactive motion platform has been presented here. The possibility to measure acting forces and torques makes the motion platform suitable for the use in vehicle simulators where direct interaction with a human body is required (bicycle or motorbike). The main advantage is the enhancement of the experience and the contribution to the reduction of the virtual sickness phenomenon.

We plan to extend the motion platform with a rotary axis which further improves the solution of the problem with VR sickness.

\section{ACKNOWLEDGEMENTS}

The research and development of the new interactive motion platform is supported by the company Pragolet, s.r.o. member of the Center of Intelligent Drives and Advanced Machine Control (CIDAM) supported by the Technology Agency of the Czech Republic (TACR).

\section{REFERENCES}

[1] Human-in-the-loop. Wikipedia, The Free Encyclopedia. Wikipedia, The Free Encyclopedia, 10 Dec. 2016. Web. 10 Dec. 2016.
[2] E. Thöndel. Design and Optimal Control of a Linear Electromechanical Actuator for Motion Platforms with Six Degrees of Freedom. 2011, Intelligent Automation and Systems Engineering, Springer, 65-77.

[3] E. Thöndel. Design and Optimization of a Motion Cueing Algorithm for a Truck Simulator. 2012, In Proceeding of the 2012 European simulation and modeling Conference, Essen, Germany, 165-170.

[4] E. Thöndel. Model Predictive Motion Cueing Algorithm For a Truck Simulator. 2013, In Proceeding of the 2013 European simulation and modeling Conference, Lancaster, United Kingdom, 188-192.

[5] P. members. Vývoj zpětnovazebního rehabilitačního přistroje založenÃlho na principu pohybové terapie. Research Project, https://www.rvvi.cz/cep?ss=detail\&h=TA03010313 2015.

[6] P. contributors. 4D VR Experience Modul. The Global Association for Marketing at Retail, POPAI Awards 2016, http://www.popai.cz/files/tinymce/files/ popai\%20awards\%202016/vyher/20.pdf, 2016.

[7] O. contributors. Oculus Rift VR Motion Sickness. Oculus http:

//riftinfo.com/oculus-rift-motion-sickness/ -11-techniques-to-prevent-it, 2016.

[8] R. contributors. Yaw Motion Sickness. http://www.rotovr.com, 2016. 